\title{
Carbonation-induced volume change in alkali-activated slag
}

2

\author{
Hailong Ye*, Aleksandra Radlińska
}

Department of Civil and Environmental Engineering, The Pennsylvania State University, 3127

Research Drive, State College, PA, 16801, United States

* Corresponding author. Email: huy131@ psu.edu Phone: +001 484-260-4003

Abstract: In this work, the volume changes of alkali-activated slag (AAS) paste prepared using various types of activator were characterized at nitrogen and atmospheric conditions. The results show that atmospheric carbonation of AAS results in volumetric expansion and disintegration, which may be attributed to the generation of crystallization stress in restrained pore spaces. This study suggests that the carbonation-induced volume change in cementitious materials is a combined result of chemical reactions and physical characteristics, depending on hydrated phase assemblage, composition, and pore structure of cementitious solids. The potassium ions $\left(\mathrm{K}^{+}\right)$, compared to sodium ions $\left(\mathrm{Na}^{+}\right)$, can enter the interlayer space of calcium-alumina-silicatehydrate $(\mathrm{C}-\mathrm{A}-\mathrm{S}-\mathrm{H})$, distort the C-A-S-H layers stacking, coarsen the pore structure, and make AAS more vulnerable to carbonation. It is suggested that the high alkali content in AAS systems contributes considerably to its poor volumetric stability under carbonation.

Keywords: Alkali-activated slag; Volume change mechanism; Crystal growth model; Alkalis;

\section{Calcium-alumina-silicate-hydrate}




\section{Introduction}

25 Alkali-activated slag (AAS) binder is typically produced by chemical reaction between groundgranulated blast-furnace slag and an alkaline solution (e.g. sodium hydroxide or silicates) [1-3].

27 Since blast-furnace slag is a by-product of iron ore smelting, the production of AAS can improve the sustainability of concrete products by lowering the embodied energy and greenhouse gas emissions, as compared to ordinary portland cement (OPC) [4, 5]. Although AAS exhibits wellestablished environmental benefits and promising mechanical properties, its broader acceptance

31 is hindered by concerns regarding its long-term durability $[2,5]$. One major obstacle inhibiting

32 the practical application of AAS is their poor volumetric stability at atmospheric condition [5].

33 Previous studies have shown that AAS exhibits large chemical, autogenous, and drying 34 shrinkage [6-11], rapid carbonation [12, 13], and extensive micro-cracking [14], in comparison to OPC. However, the mechanisms of volumetric instability of AAS at atmospheric condition 36 have not been fully understood.

When hardened cementitious materials are exposed to the atmosphere, drying and carbonation 39 occur simultaneously. The low relative humidity $(\mathrm{RH})$ in ambient drives water evaporation from the drying surfaces of cementitious solids, inducing flow of liquid and diffusion of vapor in the 41 interior of materials $[15,16]$. During drying process, the menisci are formed in the pores, which 42 generate hydrostatic tensile stress (i.e. capillary stress) that pulls adjacent pore walls closer, 43 resulting in drying shrinkage [16-18]. In the meantime, atmospheric $\mathrm{CO}_{2}$ dissolves in the pore 44 water and forms carbonic acid. The reaction of carbonic acid with the existing anion leads to the carbonation of pore solution, resulting in $\mathrm{pH}$ reduction and precipitation of alkali-containing 46 carbonates [19]. The solid phases formed in AAS, including calcium-alumina-silicate-hydrate 
47 (C-A-S-H) and other secondary products, may undergo dissolution, decomposition, or

48 decalcification. The carbonation of solid phases can result in a volume change of bulk materials,

49 which is typically referred to as carbonation shrinkage.

50

51 The explanation for the carbonation shrinkage of cementitious materials remains unclear because

52 carbonation theoretically results in an increase in unit cell volume whether the product is calcite,

53 aragonite, or vaterite. Several mechanisms for the carbonation shrinkage of OPC paste have been

54 proposed. For example, Powers [20] attributed the carbonation shrinkage to the dissolution of

55 portlandite crystals, which are under crystallization pressure. As such, carbonation shrinkage is

56 the result of crystallization pressure reduction, while precipitation of calcite in the pores does not

57 exert crystallization pressure on the solid skeleton. Based on the Power's theory, the carbonation

58 shrinkage of AAS should be lower than that of OPC paste, due to the little amount of portlandite

59 formation in AAS. By contrast, Chen et al. [21] argued that the proportion of carbonation

60 shrinkage in OPC paste induced by portlandite dissolution is relatively small compared to that

61 induced by decalcification of calcium-silicate-hydrate (C-S-H). They suggested that the

62 decalcification shrinkage of cement paste is primarily due to the nanostructure changes of C-S-H,

63 which eventually decomposes into silica gels. As also reported by Matsushita et al. [22], in C-S-

$64 \mathrm{H}$, the $\mathrm{Ca}$ ions dissolved from the $\mathrm{Ca}-\mathrm{O}$ layer and the double-chain silicate anion structures were

65 decomposed, shrunk and were polymerized to the silica-gel-like structure. In agreement with this

66 reasoning, the $\mathrm{C}-\mathrm{A}-\mathrm{S}-\mathrm{H}$ in $\mathrm{AAS}$ should exhibit greater decalcification shrinkage than the $\mathrm{C}-\mathrm{S}-\mathrm{H}$

67 in OPC paste due to its much lower $\mathrm{Ca} / \mathrm{Si}$ ratio.

68 
Although a significant amount of work has been done on characterizing the carbonation

70 characteristics of AAS, to the best of authors' knowledge, no one has ever investigated the

71 volume changes of AAS during carbonation process. Previous research shows that AAS is more

72 intensely and deeply carbonated than OPC $[12,13]$. Due to the insufficient amount of portlandite

73 in AAS, carbonation directly affects gels, causing decalcification, loss of cohesion and strength,

74 and micro-cracking $[12,13,19]$. However, it is still unknown if the volumetric instability of

75 AAS observed at atmospheric condition is a result of large carbonation shrinkage or drying

76 shrinkage (due to the reduction of $\mathrm{RH}$ ) or both. Distinguishing the volume change mechanism

77 due to drying and carbonation is important since it provides the fundamental knowledge about

78 the origins of poor volumetric stability of AAS.

79

80 To fill the aforementioned knowledge gaps, this study investigates the shrinkage performance of

81 AAS prepared with various alkaline solutions at both nitrogen and atmospheric conditions. The

82 goal of this research is to provide a better understanding of the mechanisms of volumetric

83 instability of alkali-activated materials and potentially provide new insights on finding effective

84 shrinkage cracking mitigation strategies.

85

86

\section{2. Experimental procedure}

88

\subsection{Materials}

89 A Grade 120 ground granulated blast-furnace slag with a specific gravity of 2.89 was used in this

90 work. The slag composition as measured using inductively coupled plasma atomic emission

91 spectroscopy (ICP-AES) method is listed in Table 1. The X-ray diffraction analysis indicates that 
92 the slag contains primarily amorphous structure with a trace amount of gypsum and monoclinic 93 alite. The broad and diffuse peak in the range $2 \theta=30^{\circ}$ to $31.6^{\circ}$ (see Figure 1 ) is the result of the

94 short range order of the aluminosilicate glass structure in slag [3, 11].

95

\subsection{Specimen preparation}

97 Four different types of alkaline solution were prepared in order to investigate the effects of type of alkali salts on the hydrated phases assemblage, pore structure, and shrinkage performance of AAS. To prepare activators, alkali salts pellets or powders, i.e. sodium hydroxide $(\mathrm{NaOH})$, sodium chloride $(\mathrm{NaCl})$, sodium carbonate $\left(\mathrm{Na}_{2} \mathrm{CO}_{3}\right)$, and potassium hydroxide $(\mathrm{KOH})$, were dissolved in distilled water, to reach the targeted concentration and composition shown in Table types of anion on the behaviors of AAS. The volumetric activator- to-slag ratio was kept constant at 1.45 for all four mixtures. The prepared activators were sealed in airtight containers to prevent carbonation and evaporation and shaken continuously to create a homogenous solution before 106 mixing.

After mixing according to ASTM C305-12, a non-standardized mold was designed to cast "minibar" prism specimens of a dimension of $12.7 \mathrm{~mm} \times 12.7 \mathrm{~mm} \times 139.7 \mathrm{~mm}(1 / 2$ inch $\times 1 / 2 \mathrm{inch} \times 51 / 2$ inches). The small geometry enabled the specimens to reach equilibrium with environments in a

111 much shorter time, in comparison to the conventional size. The specimens were further cured in 112 a moist room $\left(100 \% \mathrm{RH}, 23 \pm 0.5^{\circ} \mathrm{C}\right)$ for $24 \mathrm{~h}$ before demolding. 
115 In order to investigate the effects of carbonation on volume change of AAS, samples were placed

116 in two drying environments after demolding:

118 Nitrogen gas condition: A Vena VC-10 environmental chamber was programmed at 50\% RH 119 and $23 \pm 0.5^{\circ} \mathrm{C}$. To prevent carbonation of AAS during experiments, dry nitrogen $\left(\mathrm{N}_{2}\right)$ was purged 120 in chambers continuously and the concentration of $\mathrm{CO}_{2}$ was periodically checked with a portable $121 \mathrm{CO}_{2}$ analyzer to confirm consistent $0 \mathrm{ppm}$.

122

123 Atmospheric condition: A walk-in environmental chamber which was maintained at $50 \pm 4 \% \mathrm{RH}$ 124 and $23 \pm 0.5^{\circ} \mathrm{C}$ was used. The concentration of $\mathrm{CO}_{2}$ in that room was measured to be $400 \mathrm{ppm}$.

125

126 The changes in length and weight of AAS paste specimens were recorded, utilizing a modified 127 digital comparator with a measuring precision of 0.0001 inch and a balance with a measuring 128 accuracy of $0.01 \mathrm{~g}$.

130 In the meantime, the same batch of AAS paste was cast in a series of sealed vials (stored in a 131 moist room with $100 \% \mathrm{RH}$ and $23 \pm 0.5^{\circ} \mathrm{C}$ ) to investigate the effects of alkali salts on the hydrated 132 phase assemblage and pore structure of AAS. X-ray diffraction (XRD) was used to investigate 133 the hydrated phase assemblage evolution of AAS paste at $1 \mathrm{~d}, 7 \mathrm{~d}$, and $28 \mathrm{~d}$. Scanning electron 134 microscopy equipped with X-ray microanalysis (SEM/EDS) and mercury intrusion porosimetry 135 (MIP) were used to investigate the composition, hydrated phase assemblage, and pore structure 136 of AAS paste at $28 \mathrm{~d}$. 
138 In order to investigate the effects of carbonation on the phase assemblage and microstructure of 139 AAS paste, at the end of shrinkage measurements (for nitrogen gas condition it was at the age of $140114 \mathrm{~d}$, while for atmospheric condition it was 55d), the samples were collected for XRD and field 141 emission scanning electron microscope (FESEM) analysis. Given the fact that the level of 142 carbonation may be inhomogeneous across the cross section of specimens, the entire 'mini-bar' 143 specimens were implemented. However, based on the experimental results, it is believed that the 144 carbonation of specimens was almost complete. The detailed description of the implemented 145 techniques is included in the Sections 2.4-2.7. Prior to testing, the solvent-exchange method (i.e. 146 immersion in isopropyl alcohol for two weeks and then vacuum drying for one week) was 147 adopted to preserve the phases and microstructure of samples.

150 The AAS paste samples were crushed and milled for about 15 minutes, and further front-filled 151 into a zero-background plate. XRD data was collected using a PANalytical Empyrean 152 diffractometer in a conventional Bragg-Brentano $\theta-2 \theta$ configuration. CuK $\alpha$ X-ray $(\lambda=1.5418 \AA)$ 153 was generated using $40 \mathrm{~mA}$ and $45 \mathrm{kV}$ operating conditions. A beta-filter Nickle was used to 154 remove the $\beta$ diffraction spectrums. Incident beam Soller slits of 0.04 radians were used, and the 155 incident divergence and anti-scatter slits were fixed at $0.25^{\circ}$ and $0.5^{\circ}$, respectively. The samples were scanned continuously between $5^{\circ}$ and $45^{\circ} 2 \theta$ under these conditions.

\subsection{Scanning electron microscopy with $X$-ray microanalysis (SEM/EDS)}

159 FEI Quanta 200 equipped with X-ray microanalysis was used to investigate the composition of 160 hydrated phases in AAS. The samples were first impregnated with a low viscosity epoxy in 
161 desiccators, and the surface epoxy was polished off and the specimens were polished down to

$1621 \mu \mathrm{m}$. More than 50 EDS microanalysis data points were collected randomly across the hydrated

163 matrix for each specimen.

164

165

2.6 Mercury intrusion porosimetry (MIP)

166 Micromeritics AutoPore V Model 9620, which is capable of measuring pore diameters ranging

167 from 360 to $0.003 \mu \mathrm{m}$, was implemented to characterize the pore structure (e.g. pore entry size

168 distribution, porosity) of AAS paste samples.

169

170

2.7 Field emission scanning electron microscope (FESEM)

171 FEI NanoSEM 630 equipped with secondary electron detector was adopted to investigate the

172 microstructure and morphology of hydrated products in AAS. Fractured samples were directly

173 loaded under detector after carbon coating.

174

175

1763 Results and Discussion

177 3.1 Phase assemblage

178 Figure 1 shows the XRD patterns of slag and AAS paste cured for $1 \mathrm{~d}, 7 \mathrm{~d}$, and $28 \mathrm{~d}$. It can be seen 179 that the main identified crystalline phases in AAS are C-S-H (I), portlandite, hydrotalcite-like 180 (Mg-Al) phase, and sodium calcium alumina sulfate hydrate, regardless of the activator type [11, 181 23]. In comparison to NH mixture, the addition of chloride in NL mixture results in the Friedel's 182 salt formation. For potassium-activated slag, the interlayer thickness and the peak shape of C-S$183 \mathrm{H}(\mathrm{I})$ are larger and more diffusive, in comparison to those in sodium-activated slag mixtures. It 
184 indicates that the binding mechanisms of $\mathrm{Na}^{+}$and $\mathrm{K}^{+}$on the hydrated phases of AAS are

185 different. It seems that the $\mathrm{K}^{+}$can extensively enter the interlayer space [24], which may distort 186 the stacking regulation of C-A-S-H layers. In addition, cordierite and dipotassium sulfate were 187 exclusively detected in potassium-activated slag. For NC mixture, the peak intensities of phases, 188 especially C-S-H (I) and Mg-Al phases, seem to be slightly stronger, which may be attributed to 189 the additional activation effect of sodium carbonate.

191 Figure 2 shows the EDS atomic relationship in the solid hydrated phases of AAS paste at 28d. $192 \mathrm{The} \mathrm{Mg} / \mathrm{Ca}$ ratio versus $\mathrm{Al} / \mathrm{Ca}$ ratio plot suggests the presence of $\mathrm{Mg}-\mathrm{Al}$ and $\mathrm{AFm}$ phases. The 193 slope of $\mathrm{Mg} / \mathrm{Ca}$ versus $\mathrm{Al} / \mathrm{Ca}$ obtained by least square regression analysis provides the estimation 194 of $\mathrm{Mg} / \mathrm{Al}$ ratio of $\mathrm{Mg}-\mathrm{Al}$ phase, which is about 2.04 for $\mathrm{NH}$ mixture, 1.55 and 1.60 for $\mathrm{NC}$ and $195 \mathrm{KH}$ mixture, and 1.1 for NL mixture. In addition, the strong linear correlation between $\mathrm{Al} / \mathrm{Ca}$ 196 ratio versus $\mathrm{Si} / \mathrm{Ca}$ ratio indicates the structural substitution of $\mathrm{Al}^{3+}$ for $\mathrm{Si}^{4+}$ in the tetrahedral 197 silicate chain of C-A-S-H $[25,26]$. Based on the regression analysis, the type of cation (e.g. $\mathrm{Na}^{+}$, $198 \mathrm{~K}^{+}$) does not substantially affect the incorporation of $\mathrm{Al}^{3+}$ in C-A-S-H. On the other hand, the 199 strong correlation between $(\mathrm{Na}+\mathrm{K}) / \mathrm{Ca}$ versus $\mathrm{Si} / \mathrm{Ca}$ for sodium-activated slag implies the alkali 200 binding on the hydrated phases [27]. This binding mechanism may be a result of structural 201 incorporation of alkalis into the silicate structure, or a physical adsorption at the surface of C-A$202 \mathrm{~S}-\mathrm{H}[28]$. At the same $\mathrm{Ca} / \mathrm{Si}$ ratio, the amount of bound sodium in NL and NC mixtures tends to 203 be higher than that of NH mixture, which is likely due to the initial higher sodium concentration 204 in the pore solution. By contrast, for potassium-activated slag, the retention of alkalis is 205 substantially higher than that of sodium-activated slag, and no correlation between $(\mathrm{Na}+\mathrm{K}) / \mathrm{Ca}$ 206 and Si/Ca can be clearly observed. It may be attributed to the presence of potassium-rich crystals 
207 in potassium-activated slag as detected in XRD. Furthermore, it is likely that the $\mathrm{K}^{+}$, unlike $\mathrm{Na}^{+}$,

208 can access to larger surface areas or sites in C-A-S-H, and enter the interlayer space in addition

209 to the external surface adsorption and structural incorporation [24].

2113.2 Pore structure

212 Figure 3 shows the MIP pore size distribution of all AAS mixtures at $28 \mathrm{~d}$. It can be seen that the 213 addition of chloride does not dramatically change the pore size distribution of NH mixture, while 214 carbonate seems to slightly refine pore structure, although the effect is marginal. However, 215 potassium-activated slag has a substantially coarser pore structure and larger porosity than 216 sodium-activated slag.

\subsection{Length and weight changes}

219 Figure 4 (a), (b) shows the length and weight changes of AAS mixtures dried at nitrogen and 220 atmospheric conditions. At nitrogen condition, potassium-activated slag loses relatively more 221 weight and shrinks less than sodium-activated slag mixture. It may be attributed to its coarser 222 pore structure, which retains less moisture and builds lower effective capillary stress (defined as 223 the capillary stress multiplied by the degree of saturation [18]) on the solid skeleton. Similarly, 224 for sodium-activated slag, the addition of chloride and carbonate reduces the weight loss but 225 increases the magnitude of drying shrinkage. This observation simply confirms the previous 226 findings that the dominant shrinkage driving force for AAS at 50\% RH is capillary stress due to

227 meniscus formation in pores $[9,10,16]$. According to the capillary pressure theory, the radius of 228 the meniscus formed in capillary pores is primarily controlled by the ambient RH, surface 229 tension, and water activity of pore solution [16, 29]. Therefore, at the same RH under 
230 equilibrium condition, the amount of water retained in the material is a function of pore solution

231 properties and pore structure [16]. Considering that the pore size distributions of sodium-

232 activated slag are similar as obtained by MIP, the lower moisture loss in NL and NC mixtures

233 indicates lower water activities in the pore solution due to higher ionic concentrations, in

234 comparison to $\mathrm{NH}$ mixture.

236 It can be seen, from Figure 4 (a), that NL and NC mixtures show slower shrinkage kinetics, in 237 comparison to NH mixture. As evidenced from the correlation of length and weight changes for 238 AAS mixtures at nitrogen condition (see Figure 4 (c)), all mixture exhibits a visco-elastic/visco239 plastic shrinkage characteristic, in which the shrinkage magnitude continues to increase while the 240 moisture loss amount almost constant. The mechanisms of visco-elastic/visco-plastic shrinkage 241 characteristics in AAS have been extensvily studied in our previous studies $[9,10,16,30]$. This 242 shrinkage characteristic was mainly attributed to the high alkalinity in AAS, and OPC paste 243 containing alkalis shows similar performances [27, 31]. As such, the relatively higher magnitude 244 of shrinkage and delayed shrinkage kinetics in NC and NL mixtures, as compared to NH mixture, 245 can also be attributed to the higher amount of alkalis incorporated in C-A-S-H.

247 In the atmosphere, a distinctive shrinkage performance is observed for all AAS mixtures while 248 the weight change trends remain similar, in comparison to those in nitrogen condition. The 249 measurements were terminated at about 55d because all air-dried samples were disintegrated 250 with extensive micro-cracking. The length change plot (see Figure 4 (a)) shows that the AAS 251 mixtures undergo subsequent expansion after initial shrinkage. The shrinkage at early ages is 252 undoubtedly attributed to the drying, while the subsequent expansion is due to the carbonation. 
253 However, the magnitude of shrinkage at early ages is still smaller than that at nitrogen condition,

254 indicating that the effect of carbonation on volume change begins at a very early age. Therefore,

255 it is argued that carbonation does not contribute to the large shrinkage of AAS, as it actually

256 reduces it.

257

258 Figure 4 (a) also displays that potassium-activated slag starts to expand after drying for $14 \mathrm{~d}, \mathrm{NH}$ 259 and NC show expansion at 35d, and NL shows expansion after 54d. Considering that sodium260 activated slags have similar hydrated phase assemblage and pore structure, the relatively delayed 261 expansion in NL mixture may be related to protection from the slow carbonation kinetics of 262 Friedel's salt [32]. From Figure 4 (c), it can be seen that there exists an intersection point for each 263 mixture dried at nitrogen and air condition. Before that intersection point, the correlation 264 between shrinkage and moisture loss are similar for AAS dried at nitrogen and air, while after 265 that point, the samples dried at air show expansion.

266

267 3.4 Carbonation-induced phase and microstructural changes

268 Figure 5 shows the comparison of XRD patterns of AAS dried at nitrogen and atmospheric 269 conditions. The peaks corresponding to Mg-Al phase, Friedel's salt, portlandite, and C-S-H (I) 270 are significantly lower or completely gone due to carbonation, resulting in extensive formation of 271 calcite and vaterite. The significant reduction of $\mathrm{Mg}-\mathrm{Al}$ phase at air confirms that it is vulnerable 272 to carbonation and may postpone the carbonation of C-A-S-H [33], although it is clear that the 273 carbonation of $\mathrm{Mg}-\mathrm{Al}$ phase and C-S-H (I) occurs simultaneously. The main carbonation product 274 of $\mathrm{Mg}$-Al phase, which is believed to be carbonate-containing hydrotalcite [33], is however not 275 unambiguously detected in XRD. For potassium-activated slag, the extent of carbonation seems 
276 to be larger than that of sodium activated slag, as evidenced by the complete decomposition of

277 hydrated phases, which agrees with the earliest appearance of volume expansion of this mixture.

278 It indicates that the potassium makes AAS more vulnerable to carbonation, probably due to the

279 higher bound alkali content and more amorphous structure of C-A-S-H.

281 Figure 6 shows the secondary electron images of AAS dried at nitrogen condition for 114d. It 282 can be seen that various crystals can be observed in AAS, with the exact sizes and shapes 283 depending on the activator types. A distinctive morphology of C-A-S-H formed at NC mixture is 284 observed, as compared to others. As shown in Figure 7 (a), (b), it seems that convergent needle285 like $\mathrm{C}-\mathrm{A}-\mathrm{S}-\mathrm{H}$ phase forms in the non-carbonate mixture (i.e. $\mathrm{NH}$, NL, and $\mathrm{KH}$ ), while a 286 compacted foil-like C-A-S-H phase forms in NC mixture. Additionally, the morphological 287 changes are observed for AAS samples undergoing carbonation in air, as shown in Figure 7 (c), 288 (d). It clearly shows the clusters of amorphous particles (mainly calcite) depositing at the surface 289 of C-A-S-H, which is intimately mixed with or completely embed with C-A-S-H. The 290 carbonation of C-A-S-H may be responsible for the transformation from needle-like to foil-like 291 morphology. Furthermore, crystalline phases with varying shapes, sizes and morphologies, as 292 shown in Figure 7(e), (f) can be observed in air-dried samples. The sizes of these crystals 293 observed in carbonated samples are generally larger than that in non-carbonated samples shown 294 in Figure 6. The formation of these large crystals due to carbonation is believed to cause the 295 expansion and volumetric disintegration in AAS as explained in the Section 3.5. 
298 The volume expansion, micro-cracking, and disintegration of AAS dried in the air can be 299 attributed to the localized expansion in microstructure as a result of crystals growth. As carbon 300 dioxide is progressively dissolved in the pore solution, the growth of calcites (or aragonite, or 301 vaterite) nucleus begins when it is supersaturated with respect to $\mathrm{Ca}^{2+}$, carbonate acids, and 302 probably other ions (e.g. $\mathrm{Na}^{+}$). Assume that the calcite crystals is spherical with a radius of $\mathrm{r}_{\mathrm{C}}$, 303 and the interfacial free energy between carbonates crystals and pore solution is $\gamma_{C L}$, then the 304 amount of pressure that would have to be imposed to inhibit the growth of crystals can be 305 estimated as [34]:

$$
p=-\frac{2 \gamma_{C L} \cos \theta_{C L}}{r_{C}}
$$
higher concentration of solution than a macroscopic crystal. depending on the crystal curvature [35]:

$$
p=\frac{R T}{V_{C}} \ln \left(\frac{Q_{C}}{K}\right)(2)
$$

In which $\theta_{C L}$ denotes the contact angle between the crystal-pore solution interface and the pore wall. It can be seen that $p$ increases for decreasing $r_{C}$. Because of the presence of pressure $p$ on the surface of the crystal, the solubility of crystal, $Q_{C}$, shifts from the bulk solubility, $K$,

In which $K$ is the equilibrium solubility for a macroscopic crystal; $Q_{C}$ is the solubility products of crystals with a curvature of $1 / r_{C} ; R$ is the gas constant, $T$ is the absolute temperature, and $V_{C}$ is the molar volume of the crystal. Eq. (2) implies that a small crystal is in equilibrium with a

317 When the growth of crystal has not been restrained by the pore walls (i.e., $r_{C} \leq r_{p}$, where $r_{p}$ is the 318 radius of pore with a cylindrical shape), as illustrated in Figure 8 (a), the crystal continues to 
grow as far as the solubility product, $Q_{E}$, of the pore solution adjacent to the crystal is larger

320 than $Q_{C}$. Since the growth crystal has not been restrained by the pore wall, there is no

321 crystallization pressure exert on the solid skeleton. At a critical point (see Figure 8 (b)), in which

322 the crystal has just contacted with the pore walls in an equilibrium state, i.e., $r_{C}=r_{p}$, the products

323 solubility, $Q_{S}$, must be equal to $Q_{C}$. However, when crystal has contacted with the pore wall

324 (see Figure 8 (c)), and the liquid surrounding the unrestrained surface of crystals has a solubility

325 product, $Q_{E}$, larger than that $Q_{S}$, the pore wall must apply pressure to block the growth of

326 crystals. In other words, a confined crystal can only exert stress if it is in contact with a pore

327 solution that is supersaturated with respect to the unloaded face of the crystal [36]. In return, the

328 crystallization pressure, $p_{w}$, that crystal exerts on the pore wall is [37]:

329

$$
p_{w}=\frac{R T}{V_{C}} \ln \left(\frac{Q_{E}}{Q_{S}}\right), \text { where, } Q_{S}=K \cdot \exp \left(-\frac{V_{C}}{R T} \cdot \frac{2 \gamma_{C L} \cos \theta_{C L}}{r_{p}}\right) \text { (3) }
$$

It should be noted that $Q_{S}$ is dependent on the pore radius $r_{p}$. According to Eq. (3), a higher

crystallization pressure in porous materials can originate from either smaller pore sizes or higher

332 product solubility $Q_{E}$ (i.e. higher level of supersaturation). This argument is based on the assumption that the type of crystals and the interfacial free energy between crystals and pore

334 solution are similar among various systems.

336 In comparison to OPC paste, AAS has been reported to have a finer pore structure (i.e., smaller $337 r_{p}$ ) based on MIP data [8,9]; therefore, the precipitation of calcite in the restrained small pore 338 space of AAS can generate large crystallization stress, resulting in expansion and cracking. It indicates that the apparent carbonation-induced volume change in cementitious materials is not 
340 merely related to the chemical reactions, but also the physical characteristics (e.g. pore structure)

341 of cementitious microstructure. On the other hand, the presence of alkalis in the pore solution

342 may promote the formation of alkali-rich carbonates, with a relatively high $Q_{E}$. It should be

343 mentioned here that a recent study shows that atmospheric carbonation can induce expansion in

344 OPC paste containing alkalis [27]. In addition, previous studies show that the addition of alkalis

345 promotes the carbonation of $\mathrm{C}-\mathrm{S}-\mathrm{H}$, by modifying its chemical composition and structure [38,

346 39]. The increased concentration of alkalis in pore solution decreases the $\mathrm{Ca} / \mathrm{Si}$ ratio of $\mathrm{C}(-\mathrm{A})-\mathrm{S}$ -

$347 \mathrm{H}$, due to the competition effects between $\mathrm{Ca}^{2+}$ and alkali cations on compensating the negative 348 charge of deprotonated silicate chains [28]. Therefore, it is reasonable to deduce that the C-A-S-

$349 \mathrm{H}$ formed in $\mathrm{AAS}$, which has higher alkali content and lower $\mathrm{Ca} / \mathrm{Si}$ ratio, is more 350 thermodynamically vulnerable to carbonation, compared with that the C-S-H in OPC. It is 351 suggested here that the high content of alkalis in AAS systems contributes considerably to the 352 expansion and micro-cracking during carbonation.

\section{4. Conclusions}

356 In this paper, the hydrated phase assemblage, microstructure, and pore structure of AAS 357 activated by four different types of activator were characterized and their shrinkage performance 358 at two gaseous conditions (i.e. nitrogen and air) were studied. Following conclusions can be 359 drawn based on this study: 
361 (1) Carbonation shrinkage does not significantly contribute to the large shrinkage deformation of 362 AAS. In fact, carbonation of AAS in the atmosphere results in volumetric expansion and 363 subsequent disintegration.

364 (2) The origin of carbonation-induced volumetric expansion and disintegration of AAS may be 365 attributed to the crystals precipitation in refined pore space.

366 (3) Carbonation-induced volume change in cementitious materials is a combined result of the 367 chemical reactions and physical characteristics. For AAS, due to its refined pore structure, the 368 growth of carbonates can generate high crystallization stress due to restriction from pore walls.

369 (4) Carbonation of AAS results in the dissolution and decomposition of $\mathrm{Mg}$-Al phase, Friedel's 370 salt, portlandite, and C-S-H (I), forming amorphous and crystalline calcite and vaterite.

371 (5) The binding mechanisms of $\mathrm{Na}^{+}$and $\mathrm{K}^{+}$in hardened AAS are different; $\mathrm{K}^{+}$seem to enter the 372 interlayer space, distort the stacking ordering of C-A-S-H layers, and adsorbs in a larger amount 373 in AAS than $\mathrm{Na}^{+}$.

374 (6) Potassium-activated slag shows coarser pore structure, larger moisture loss, and slightly 375 lower shrinkage, in comparison to sodium-activated slag.

376 (7) It is suggested that the high alkali content in AAS systems contributes considerably to its 377 poor volumetric stability under carbonation.

381 The authors gratefully acknowledge the financial support from the U.S. National Science 382 Foundation (NSF) under Award CMMI \#1265789. Any opinions, findings and conclusions or 
383 recommendations expressed in this material are those of the authors and do not necessarily 384 reflect the views of the NSF. 
Table 1 Chemical composition (by mass \%) of slag

\begin{tabular}{lllllllllllll}
\hline \multirow{3}{*}{ Slag } & $\mathrm{CaO}$ & $\mathrm{SiO}_{2}$ & $\mathrm{Al}_{2} \mathrm{O}_{3}$ & $\mathrm{MgO}$ & $\mathrm{SO}_{3}$ & $\mathrm{~S}^{2-}$ & $\mathrm{Fe}_{2} \mathrm{O}_{3}$ & $\mathrm{Na}_{2} \mathrm{O}$ & $\mathrm{K}_{2} \mathrm{O}$ & $\mathrm{P}_{2} \mathrm{O}_{5}$ & $\mathrm{MnO}$ & $\mathrm{LOI}$ \\
\cline { 2 - 11 } & 43.83 & 30.04 & 12.74 & 4.79 & 3.11 & 0.85 & 1.16 & 0.24 & 0.40 & 0.08 & 0.22 & 2.56 \\
\hline
\end{tabular}

386

387

388

389

390

Table 2 Mix proportion for AAS paste with various alkalis

\begin{tabular}{ccc}
\hline Mixture ID & Composition of activator & Volumetric activator-to-slag ratio \\
\hline S_NH & $4 \mathrm{M} \mathrm{NaOH}$ & \\
S_NL & $4 \mathrm{M} \mathrm{NaOH}+1 \mathrm{M} \mathrm{NaCl}$ & 1.45 \\
S_NC & $4 \mathrm{M} \mathrm{NaOH}+0.5 \mathrm{M} \mathrm{Na} \mathrm{CO}_{3}$ & \\
S_KH & $4 \mathrm{M} \mathrm{KOH}$ & \\
\hline
\end{tabular}

391 Note: In the Mixture ID, N and K represent sodium and potassium, while $\mathrm{H}$, L, and C represent 392 hydroxide, chloride, and carbonates.

393

394

395

396 

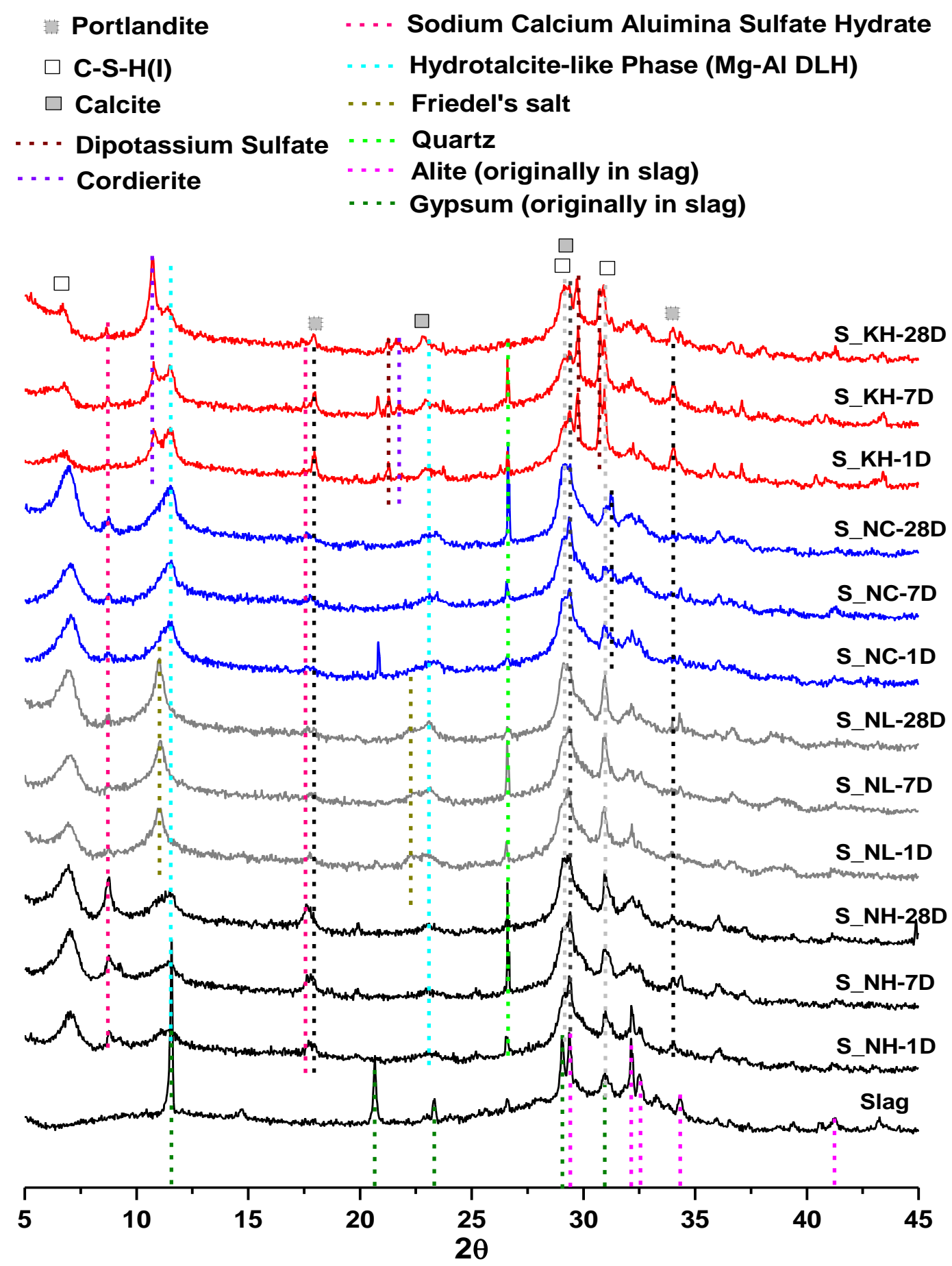

Figure 1 XRD patterns of AAS prepared with various alkaline solutions at $1 \mathrm{~d}, 7 \mathrm{~d}$ and $28 \mathrm{~d}$, which shows the evolution of hydrated phase assemblage in AAS as a function of age and type of activator. The mixture description is elaborated in Table 2. 


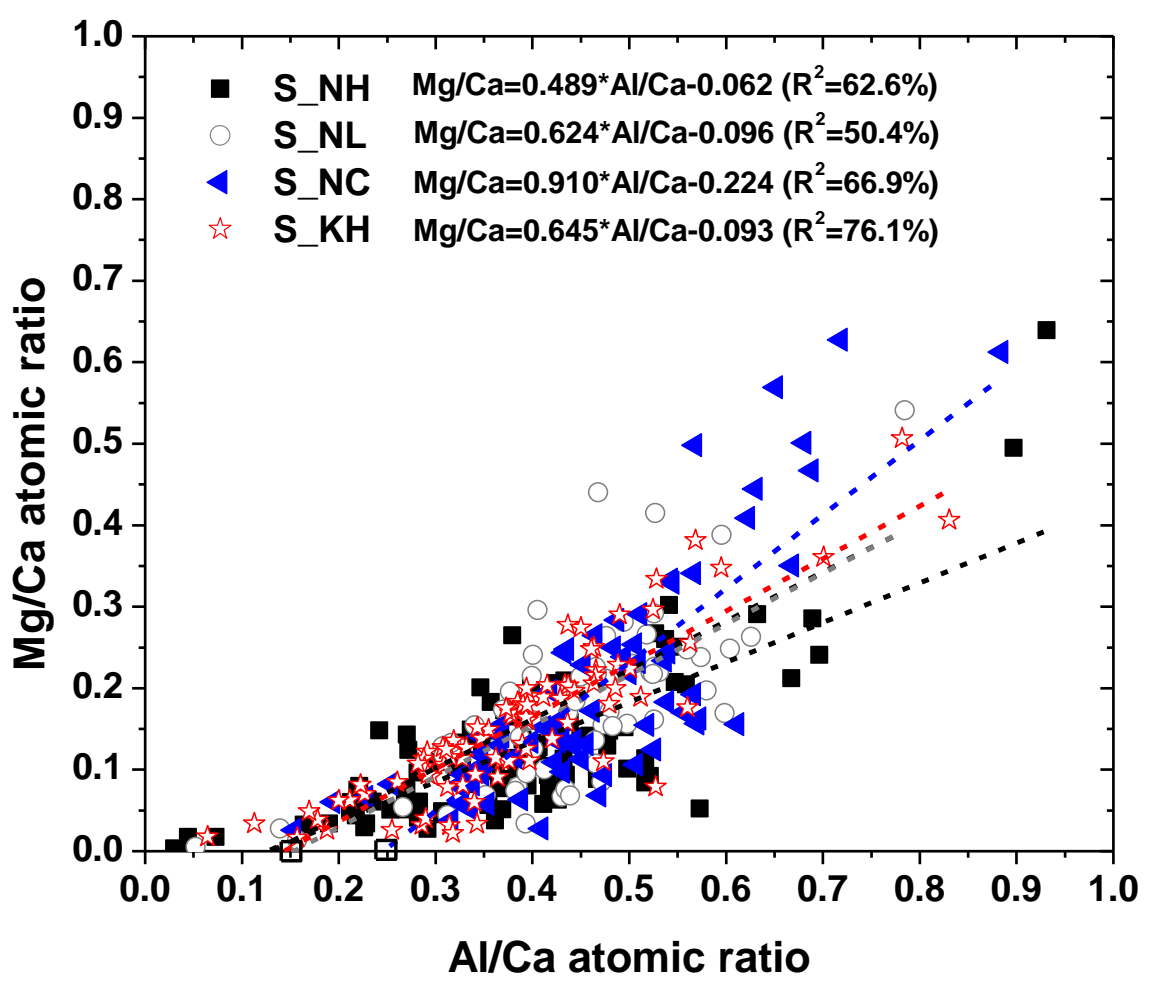

$\mathrm{Al} / \mathrm{Ca}$ atomic ratio

(a)

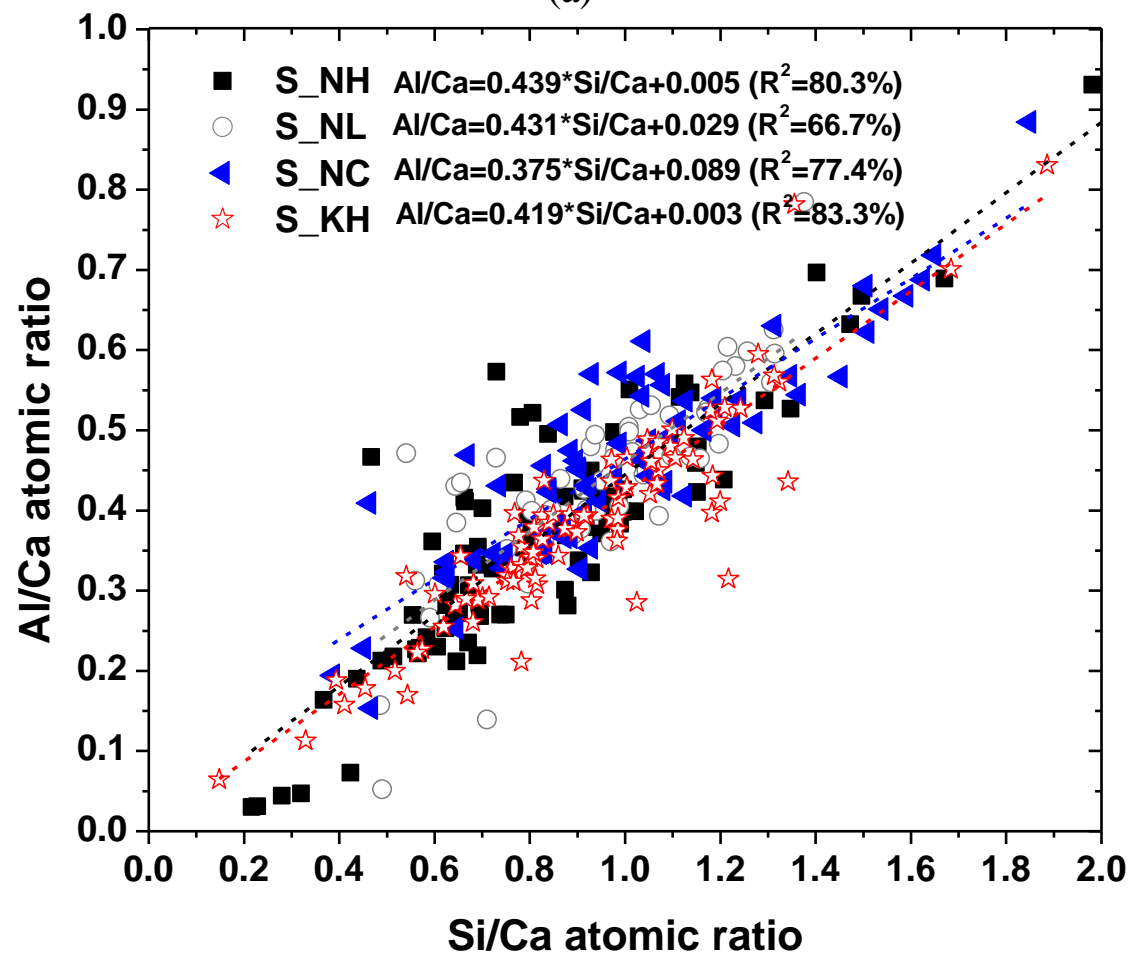

(b) 


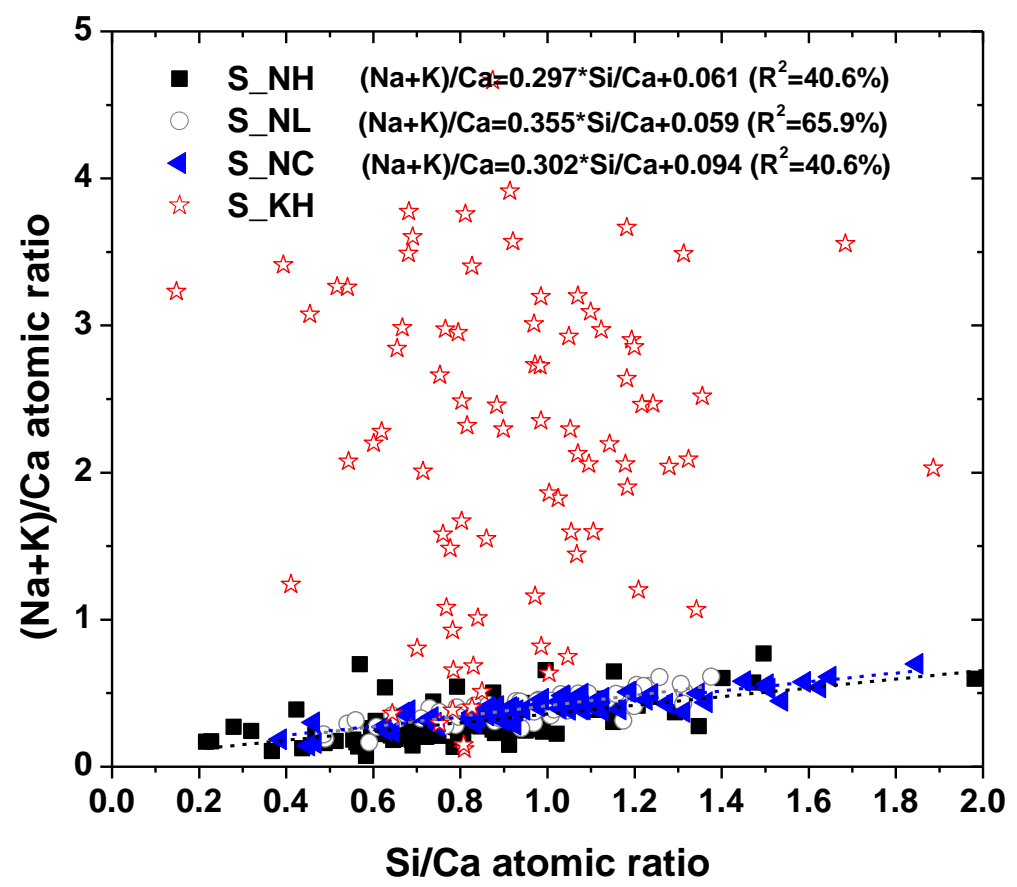

(c)

Figure 2 The atomic relationship in the solid hydrated phases of AAS (a) $\mathrm{Mg} / \mathrm{Ca}$ ratio versus $\mathrm{Al} / \mathrm{Ca}$ ratio; (b) $\mathrm{Si} / \mathrm{Ca}$ ratio versus $\mathrm{Al} / \mathrm{Ca}$ ratio; (c) $(\mathrm{Na}+\mathrm{K}) / \mathrm{Ca}$ ratio versus $\mathrm{Si} / \mathrm{Ca}$ ratio

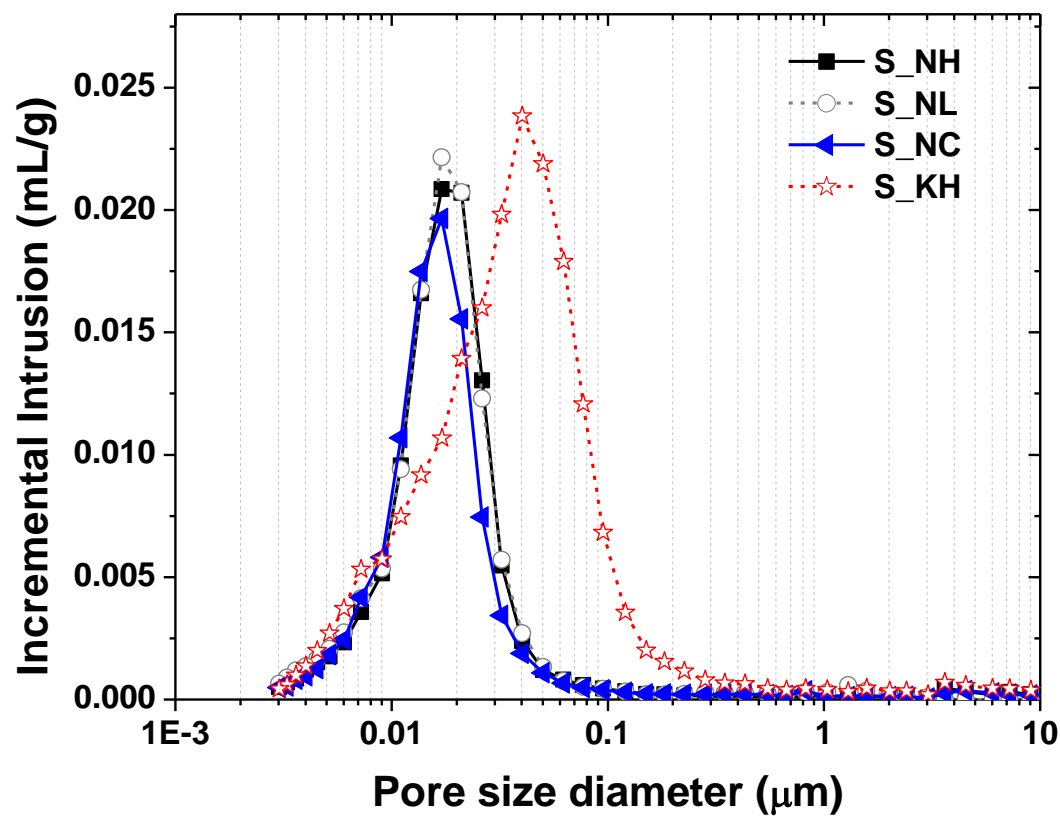

Figure 3 Pore size distribution of AAS paste cured for 28d, which shows that potassiumactivated slag has a substantially coarser pore structure than sodium-activated slag. 


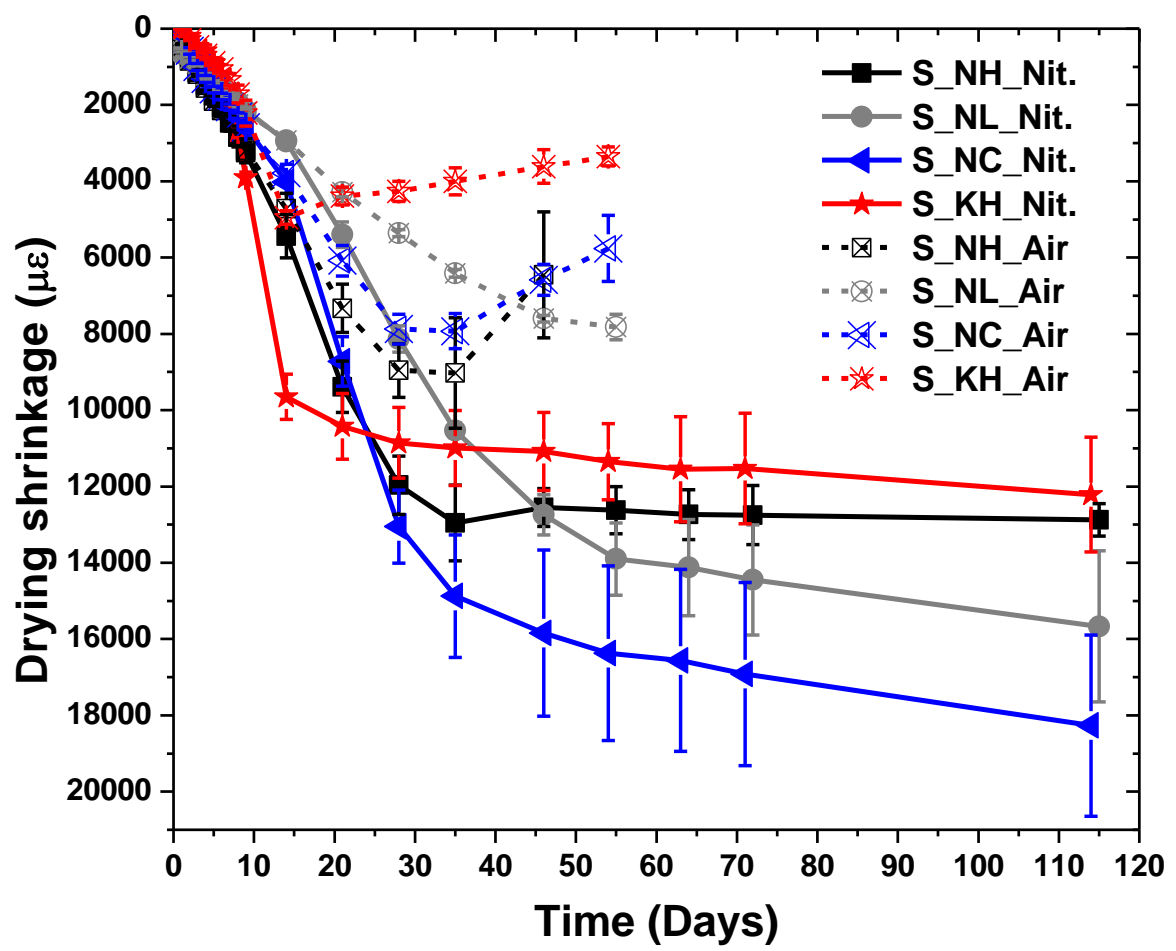

(a)

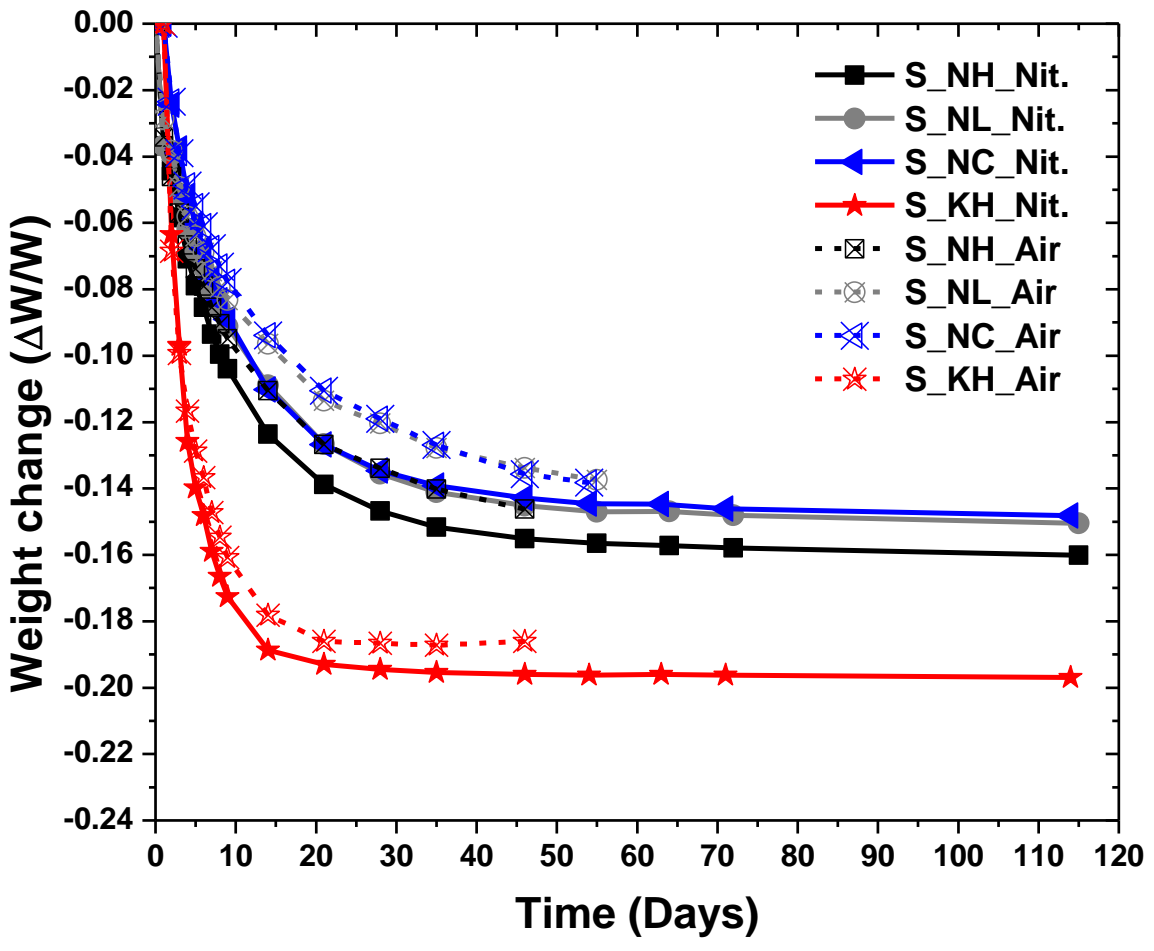

(b) 


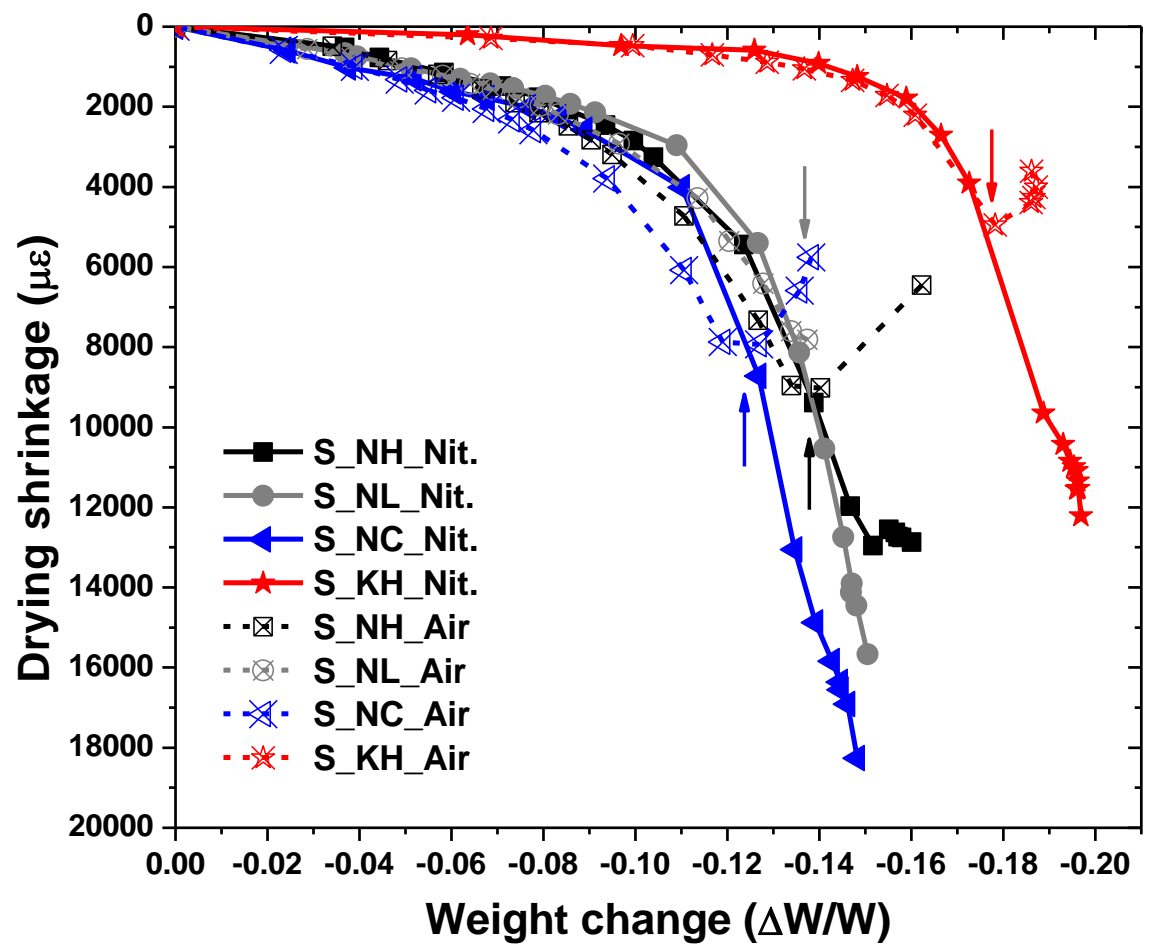

(c)

Figure 4 (a) Time-dependent shrinkage of AAS, which shows that drying at atmospheric condition results in an initial shrinkage but subsequent expansion; (b) Time-dependent moisture loss of AAS, which shows the similar trends when dried at nitrogen and atmospheric conditions; (c) Correlation of shrinkage and moisture loss of AAS, which shows the presence of intersection points. 


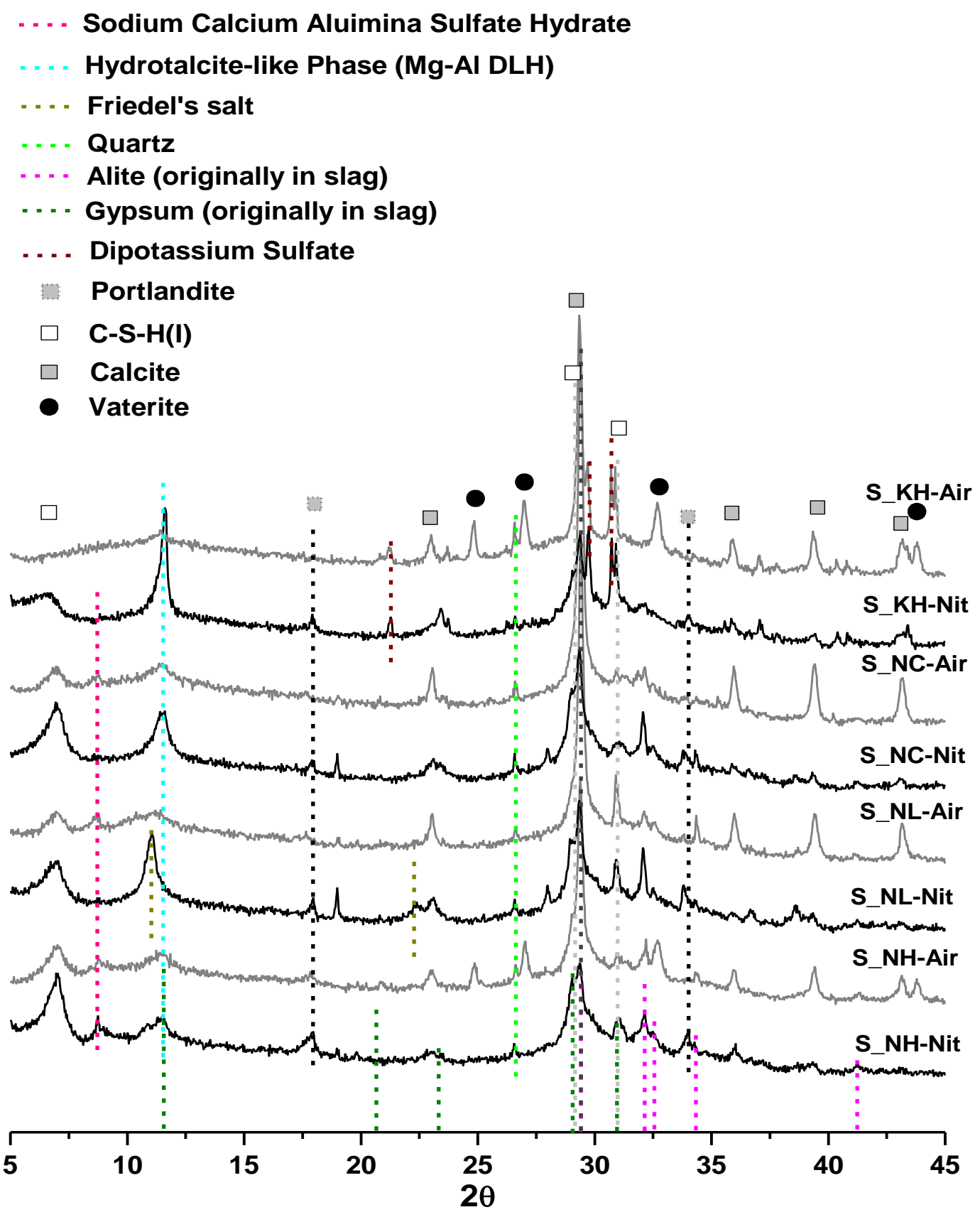

Figure $5 \mathrm{XRD}$ patterns of AAS dried at nitrogen and atmospheric conditions 


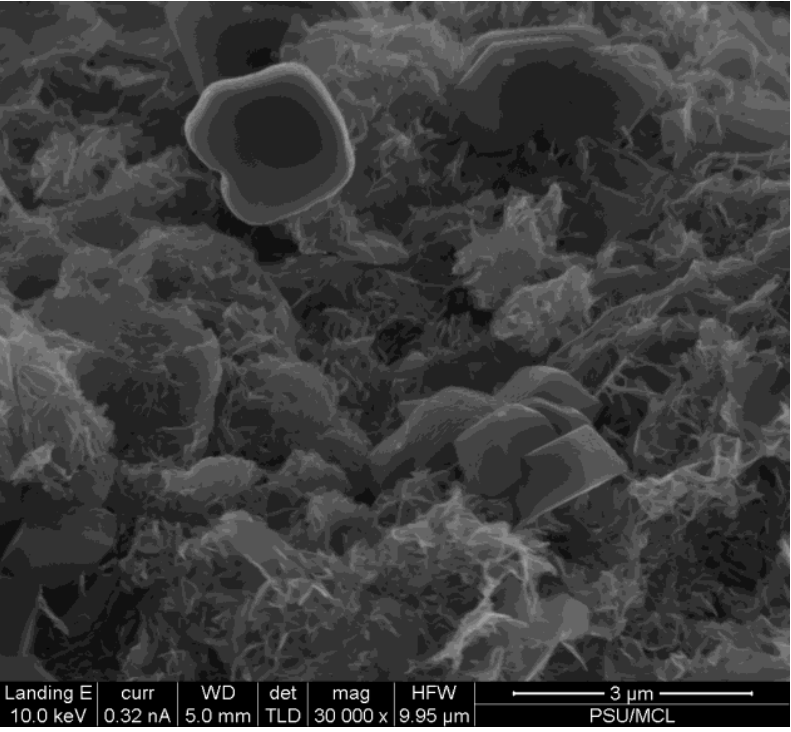

(a)

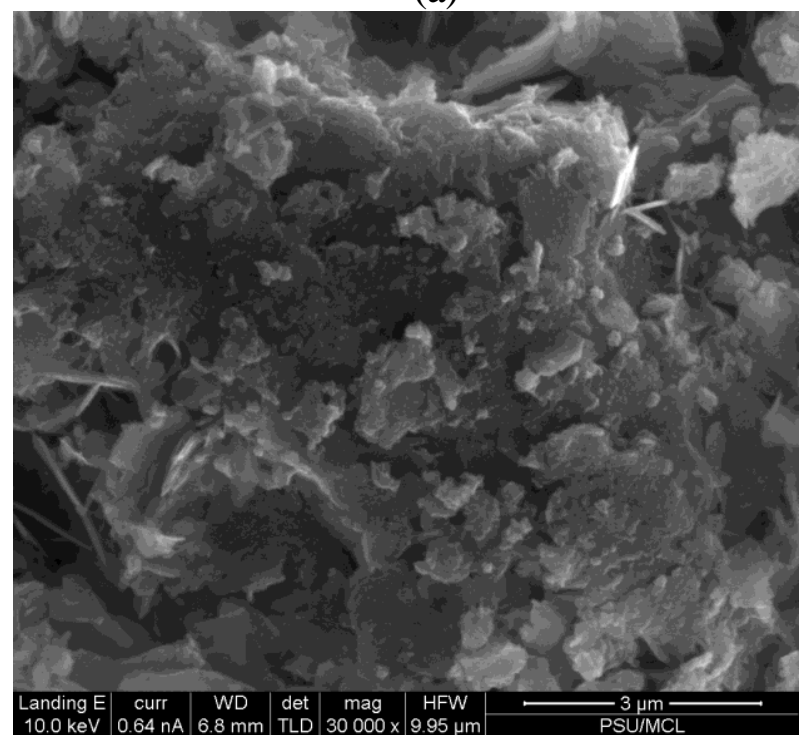

(c)

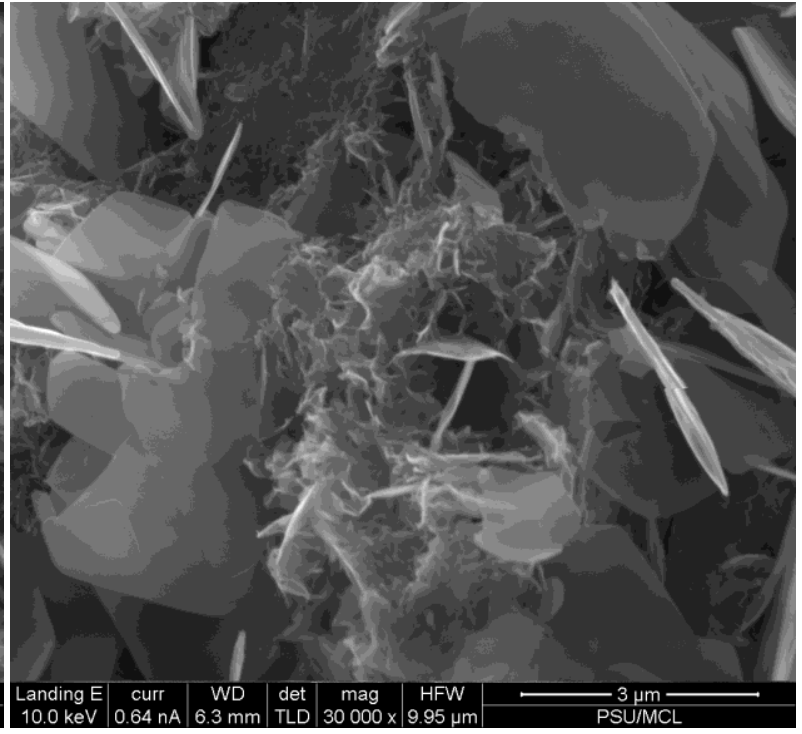

(b)

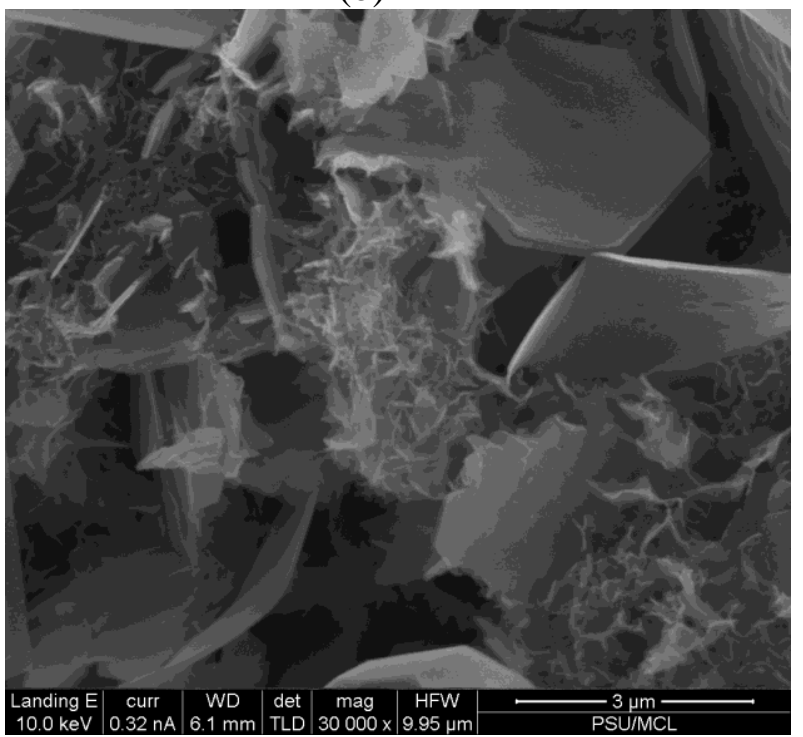

(d)
440

441

442

443

444

445

446

447
Figure 6 Secondary electron images of AAS paste dried at nitrogen condition for 114d (a) S_NH; (b) S_NL; (c) S_NC; (d) S_KH 

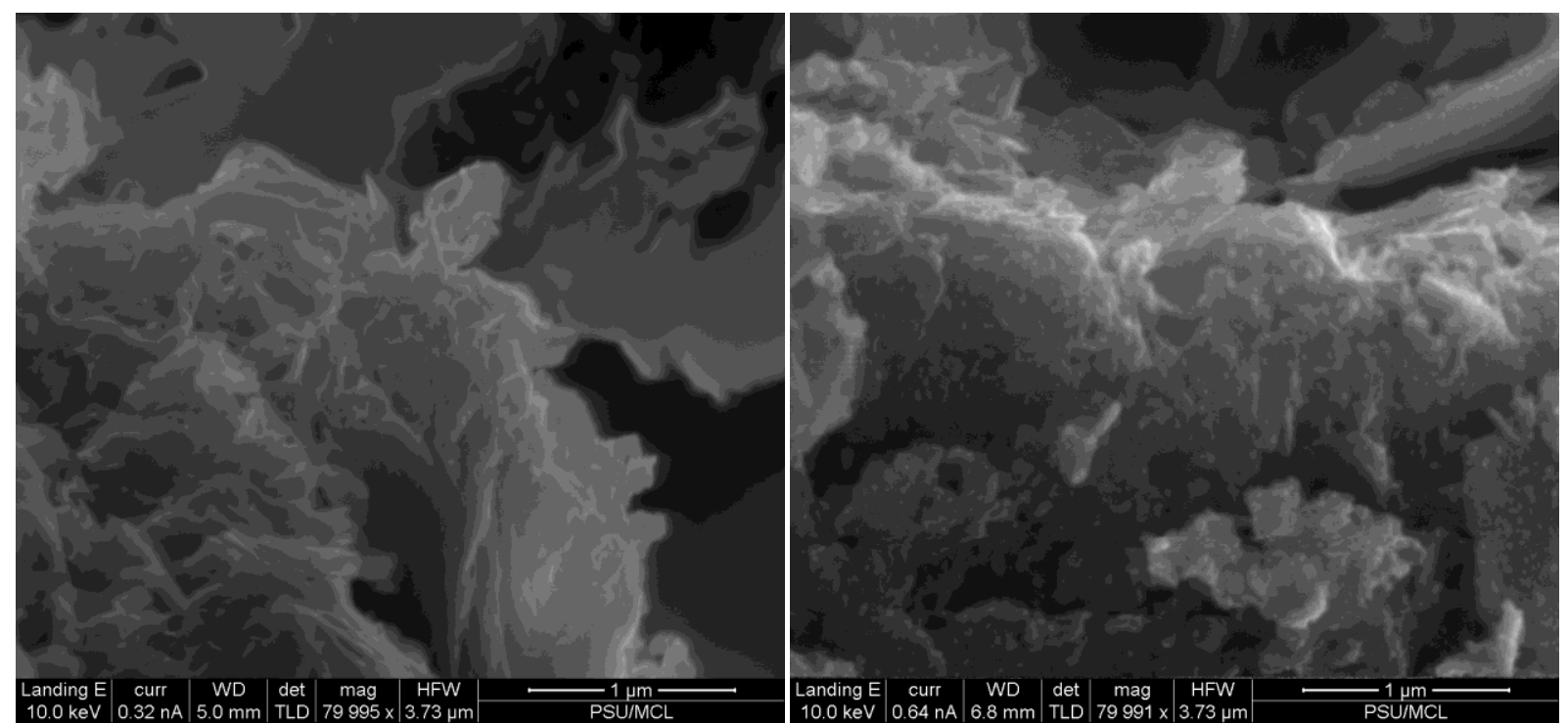

(a)

(b)

450

451

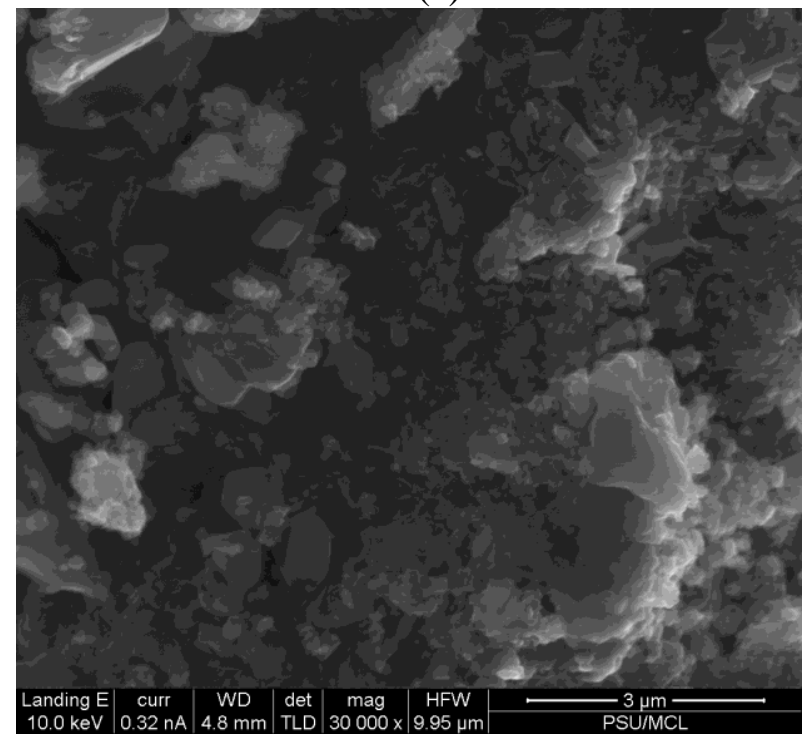

(c)

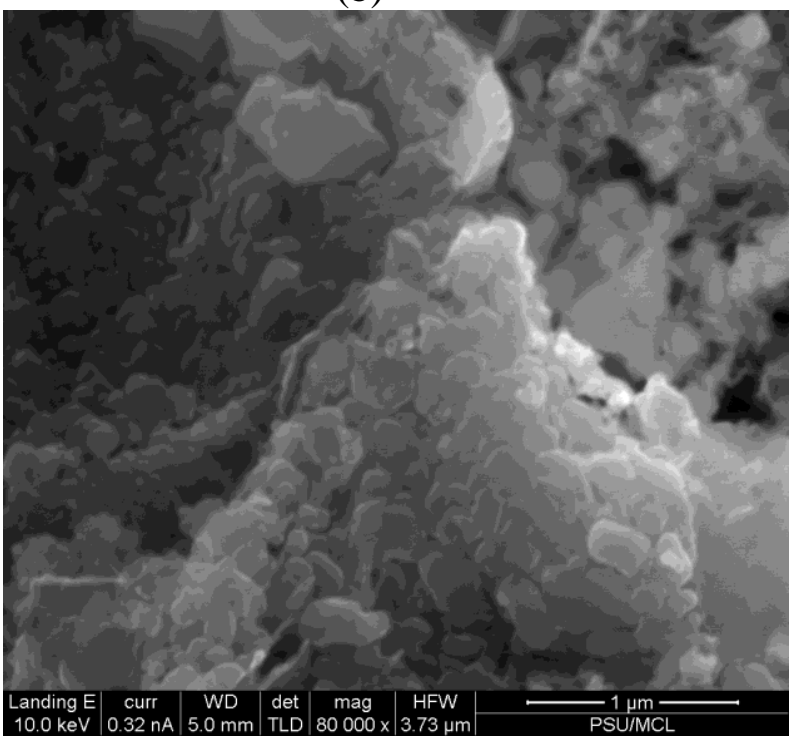

(d) 


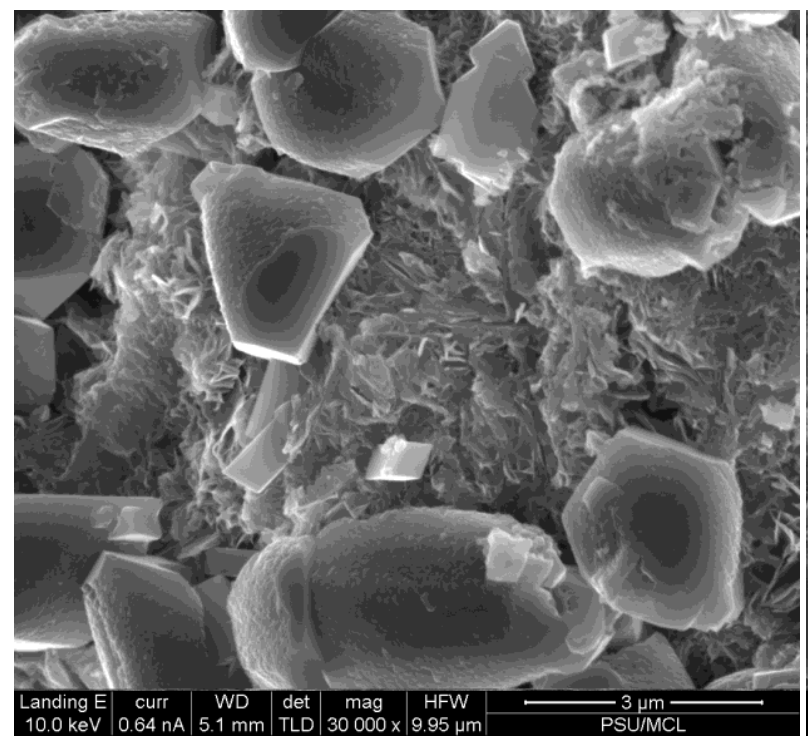

(e)

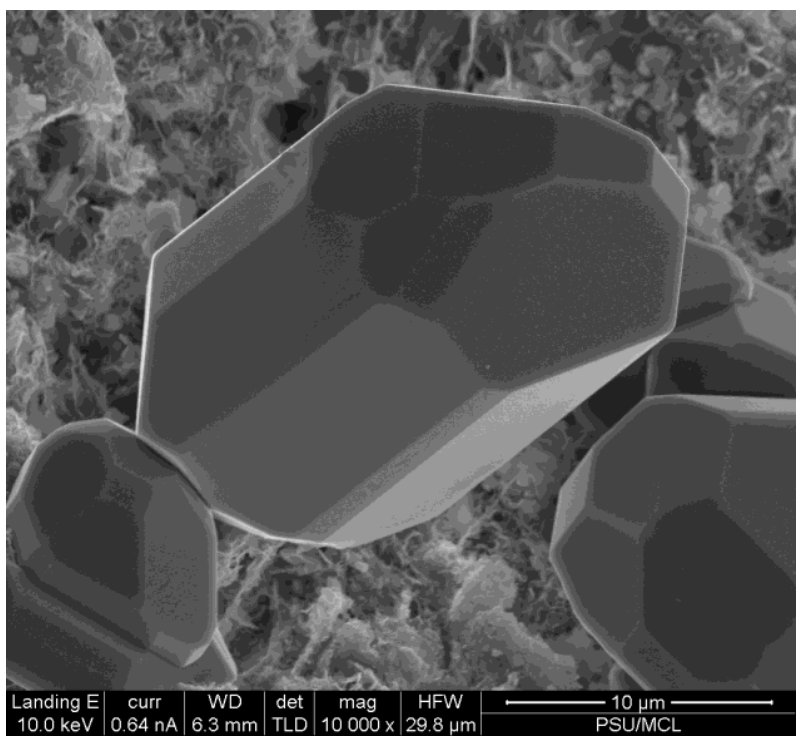

(f)

Figure 7 (a) S_NH mixture dried at nitrogen for 114d, magnification 80000x; (b) S_NC mixture dried at nitrogen for 114d, 80000x; (c) S_NH mixture dried at air for 55d, 30000x; (d) S_NH mixture dried at air for 55d, 80000x; (e) S_NC mixture dried at air for 55d, 30000x; (f) S_KH dried at air for 55d, 10000x

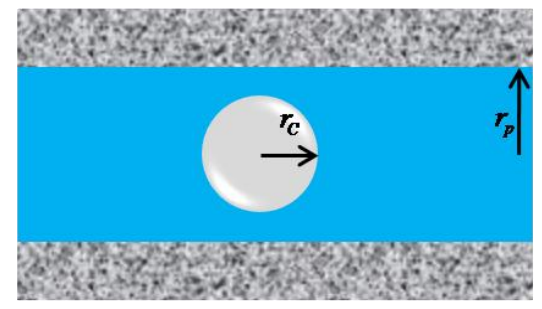

(a)

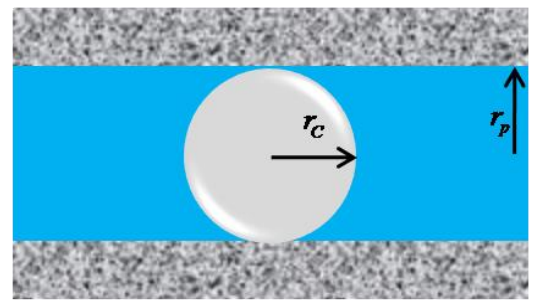

(b)

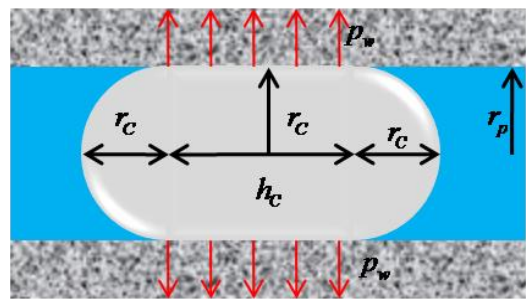

(c)

Figure 8 Illustration of crystal growing in a cylindrical pore

\section{References}

[1] M. Juenger, F. Winnefeld, J. Provis, J. Ideker, Advances in alternative cementitious binders, Cement and Concrete Research 41(12) (2011) 1232-1243.

[2] C. Shi, D. Roy, P. Krivenko, Alkali-activated cements and concretes, CRC press2006.

[3] S.-D. Wang, K.L. Scrivener, Hydration products of alkali activated slag cement, Cement and Concrete Research 25(3) (1995) 561-571.

[4] M. Jiang, X. Chen, F. Rajabipour, C.T. Hendrickson, Comparative life cycle assessment of conventional, glass powder, and alkali-activated slag concrete and mortar, Journal of Infrastructure Systems 20(4) (2014) 04014020.

[5] R.J. Thomas, H. Ye, A. Radlińska, S. Peethamparan, Alkali-activated slag concrete: A closer look at sustainable alternatives to portland cement, Concrete International 38(1) (2016) 33-38.

[6] C. Cartwright, F. Rajabipour, A. Radlińska, Shrinkage characteristics of alkali-activated slag cements, Journal of Materials in Civil Engineering 27(7) (2015) B4014007 
[7] H. Ye, C. Cartwright, F. Rajabipour, A. Radlińska, Effect of drying rate on shrinkage of alkali-activated slag cements, 4th International Conference on the Durability of Concrete Structure (ICDCS), Purdue University, Indiana, USA, 2014, pp. 254-261.

[8] F. Collins, J. Sanjayan, Effect of pore size distribution on drying shrinking of alkali-activated slag concrete, Cement and Concrete Research 30(9) (2000) 1401-1406.

[9] H. Ye, C. Cartwright, F. Rajabipour, A. Radlińska, Understanding the drying shrinkage performance of alkali-activated slag mortars, Cement and Concrete Composites 76 (2017) 13-24. [10] H. Ye, A. Radlińska, Shrinkage mechanisms of alkali-activated slag, Cement and Concrete Research 88 (2016) 126-135.

[11] H. Ye, A. Radlińska, Quantitative analysis of phase assemblage and chemical shrinkage of alkali-activated slag, Journal of Advanced Concrete Technology 14 (2016) 245-260.

[12] F. Puertas, M. Palacios, T. Vázquez, Carbonation process of alkali-activated slag mortars, Journal of Materials Science 41(10) (2006) 3071-3082.

[13] T. Bakharev, J. Sanjayan, Y.-B. Cheng, Resistance of alkali-activated slag concrete to carbonation, Cement and Concrete Research 31(9) (2001) 1277-1283.

[14] F. Collins, J. Sanjayan, Microcracking and strength development of alkali activated slag concrete, Cement and Concrete Composites 23(4) (2001) 345-352.

[15] G.W. Scherer, Theory of drying, Journal of the American Ceramic Society 73(1) (1990) 314.

[16] H. Ye, A. Radlińska, A review and comparative study of existing shrinkage prediction models for portland and non-portland cementitious materials Advances in Materials Science and Engineering 2016(2016) (2016) Article ID: 2418219.

[17] D.P. Bentz, O.M. Jensen, Mitigation strategies for autogenous shrinkage cracking, Cement and Concrete Composites 26(6) (2004) 677-685.

[18] D.P. Bentz, D.A. Quenard, V. Baroghel-Bouny, E.J. Garboczi, H.M. Jennings, Modelling drying shrinkage of cement paste and mortar Part 1. Structural models from nanometres to millimetres, Materials and Structures 28(8) (1995) 450-458.

[19] S.A. Bernal, R. San Nicolas, J.L. Provis, R.M. De Gutiérrez, J.S. van Deventer, Natural carbonation of aged alkali-activated slag concretes, Materials and Structures 47(4) (2014) 693707.

[20] T.C. Powers, A hypothesis on carbonation shrinkage, Portland Cement Association, 1900, pp. 40-45.

[21] J.J. Chen, J.J. Thomas, H.M. Jennings, Decalcification shrinkage of cement paste, Cement and concrete research 36(5) (2006) 801-809.

[22] F. Matsushita, Y. Aono, S. Shibata, Calcium silicate structure and carbonation shrinkage of a tobermorite-based material, Cement and Concrete Research 34(7) (2004) 1251-1257.

[23] H. Ye, A. Radlińska, Fly ash-slag interaction during alkaline activation: Influence of activators on phase assemblage and microstructure formation, Construction and Building Materials 122 (2016) 594-606.

[24] T. Bach, E. Chabas, I. Pochard, C.C.D. Coumes, J. Haas, F. Frizon, A. Nonat, Retention of alkali ions by hydrated low-pH cements: Mechanism and $\mathrm{Na}+\mathrm{K}+$ selectivity, Cement and Concrete Research 51 (2013) 14-21.

[25] I. Richardson, A. Brough, G. Groves, C. Dobson, The characterization of hardened alkaliactivated blast-furnace slag pastes and the nature of the calcium silicate hydrate (CSH) phase, Cement and Concrete Research 24(5) (1994) 813-829. 
[26] I. Richardson, The nature of CSH in hardened cements, cement and concrete research 29(8) (1999) 1131-1147.

[27] H. Ye, A. Radlińska, J. Neves, Drying and carbonation shrinkage of cement paste containing alkalis, Materials and Structures 50(2) (2017) 132.

[28] B. Lothenbach, A. Nonat, Calcium silicate hydrates: Solid and liquid phase composition, Cement and Concrete Research 78 (2015) 57-70.

[29] A. Radlinska, F. Rajabipour, B. Bucher, R. Henkensiefken, G. Sant, J. Weiss, Shrinkage mitigation strategies in cementitious systems: A closer look at differences in sealed and unsealed behavior, Transportation Research Record: Journal of the Transportation Research Board (2070) (2008) 59-67.

[30] H. Ye, Creep Mechanisms of Calcium-Silicate-Hydrate: An Overview of Recent Advances and Challenges, International Journal of Concrete Structures and Materials 9(4) (2015) 453-462. [31] M.C.G. Juenger, H.M. Jennings, Effects of high alkalinity on cement pastes, ACI Materials Journal 98(3) (2001).

[32] A. Suryavanshi, R.N. Swamy, Stability of Friedel's salt in carbonated concrete structural elements, Cement and Concrete Research 26(5) (1996) 729-741.

[33] S.A. Bernal, R. San Nicolas, R.J. Myers, R.M. de Gutiérrez, F. Puertas, J.S. van Deventer, J.L. Provis, $\mathrm{MgO}$ content of slag controls phase evolution and structural changes induced by accelerated carbonation in alkali-activated binders, Cement and Concrete Research 57 (2014) 3343.

[34] A.W. Adamson, A.P. Gast, Physical chemistry of surfaces, (1967).

[35] C.W. Correns, Growth and dissolution of crystals under linear pressure, Discussions of the Faraday society 5 (1949) 267-271.

[36] M. Steiger, Crystal growth in porous materials-I: the crystallization pressure of large crystals, Journal of crystal growth 282(3) (2005) 455-469.

[37] G.W. Scherer, Crystallization in pores, Cement and Concrete research 29(8) (1999) 13471358.

[38] I.G. Lodeiro, D. Macphee, A. Palomo, A. Fernández-Jiménez, Effect of alkalis on fresh CS-H gels. FTIR analysis, Cement and Concrete Research 39(3) (2009) 147-153.

[39] K. Kobayashi, Y. Uno, Influence of alkali on carbonation of concrete, part 2-influence of alkali in cement on rate of carbonation of concrete, Cement and Concrete Research 20(4) (1990) 619-622. 